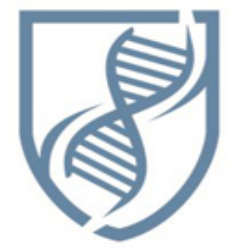

Journal of Bioscience and Applied Research
JBAAR

WWW.JBAAR.ORG

\title{
Comparative cardioprotective effect of Egyptian Silybum marianum extract and Chinese silymarin in experimentally liver fibrosis
}

\author{
${ }^{1}$ Ehab Tousson; ${ }^{2}$ Afrah F. Salama; ${ }^{3}$ Mahmoud A. Elony; and ${ }^{2 *}$ Mona A. Dora \\ ${ }^{\mathbf{1}}$ Department of Zoology; ${ }^{2}$ Biochemistry Section, Department of Chemistry; \\ ${ }^{3}$ Botany Department, Faculty of Science, Tanta University, Egypt.
}

(Corresponding author e.mail. toussonehab@yahoo.com)

\begin{abstract}
Liver fibrosis is one of the common problems effects on the human health. Many herbal, medicinal and pharmaceutical plants and their extracts are widely studied by many researches. Chinese silymarin got a bright reputation in relieve of liver fibrosis. The current study is a comparative study between the effect of Chinese silymarin (commercial drug) and the extracted silymarin from the natural Egyptian plant on the cardiac toxicity due to liver fibrosis induced by ethanol in rats. A total of 72 female Albino rats were divided into six groups; $G_{1}$, Control; $G_{2}$,Fibrosis; $G_{3}$,Chinese silymarin; $\mathrm{G}_{4}$, Fibrosis + Chinese silymarin; $\mathrm{G}_{5}$, Egyptian silymarin extract; $\mathrm{G}_{6}$, Fibrosis + Egyptian silymarin extract. Results showed that, heart enzymes activities LDH, lipid profiles in serum and MDA in tissues were a significant increase in Fibrosis group when compared with control group. On the other hand; creatine kinase (CK) in serum, total protein, total thiol, TAC, CAT and GST in cardiac tissues were a significant decrease in Fibrosis group when compared with control group. The current results revealed that; the Egyptian plant extract improved the lipid profile, heart functions and its oxidative stress parameters as comparison with the used medical Chinese silymarin.
\end{abstract}

Keywords: Ethanol, Milk thistle extract, Silymarin, Heart, Oxidative stress, P53.

Abbreviation: ALD, alcoholic liver disease; CK, Creatine kinase; LDH, Lactate dehydrogenase; Co., Company; TP, total protein; TC, total cholesterol; HDL, high density lipoprotein; LDL, low density lipoprotein;
TG, triacylglycerol; DTNB, 5,5'-dithiobis-(2-nitrobenzoic acid); DPPH,2,2-diphenyl-1-picrylhydrazyl; MDA, malondialdehyde; CAT, catalase; GST, glutathione-stransferase; SEM, standard error deviation; IC50, inhibitory concentration; GC-MS, gas chromatographymass spectrometry; MTE, milk thistle extract; CYP2E1, cytochrome P450 2E1; GSH, glutathione; CCl4, carbon tetra chloride; TAC, total antioxidant capacity; ROS, reactive oxygen species.

\section{Introduction}

The liver regulates many important metabolic functions, so the hepatic injury is associated with distortion of these metabolic functions (Wolf, 1999). Liver is the key organ of metabolism and excretion is continuously and variedly exposed to xenobiotics because of its strategic placement in the body. Toxins absorb from the intestinal tract gain access first to the liver resulting in a variety of liver ailment (Ramachandra et al., 2007). Thus liver fibrosis is one of the common problems effects on the human health (Krishnan et al., 2012). Liver damage ranges from acute hepatitis to hepatocellular carcinoma, through apoptosis, necrosis, inflammation, immune response, fibrosis, ischemia, altered gene expression and regeneration (Poynard et al., 2000 and Friedman, 2003; Shaker et al., 2010; Salama et al., 2015). All processes that involve hepatocyte, Kupffer, stellate and endothelial cells which induce liver disease are related to the crucial role of reactive oxygen and nitrogen species. The main sources of free radicals are represented by hepatocyte mitochondria and cytochrome P450 enzymes, by endotoxin activated macrophages (Kupffer cells) and by neutrophils (Loguercio and Federico, 2003). 
The metabolism of toxic substances that enter the body occurs largely in the liver. Among these toxic substances is alcohol, which is eventually broken down into simple end products for easy elimination. Alcohol has been implicated in the genesis of liver disease. Both its consumption and metabolism promote the production of inflammatory mediators that result in hepatotoxicity and fibrogenesis. With time, leads to progressively sever liver injury and eventually cause cirrhosis (O'Shea et al., 2010). Liver fibrosis occurs when the liver is damaged (Halton et al., 2001).

Oxidative stress and associated cellular injury promote inflammation. Antioxidants could have beneficial effects in reducing the incidence of ethanol induced changes in cellular lipids, proteins and nucleic acids. They could act by reducing free radical production (Chelators of redoxactive iron derivatives), trapping free radicals themselves, interrupting the peroxidation process or reinforcing the natural antioxidant defense (Gupta, 2005; Das and Vasudevan, 2006).

Many herbal, medicinal and pharmaceutical plants and their extracts were widely studied by many researches. Silybum marianum (Milk thistle) plant got a bright reputation in relieve of the liver fibrosis and kidney damage and that might be for the potent silymarin mixture. Mechanism of action for silymarin conducted mainly to the antioxidant, anti-inflammatory, antifibrotic and antilipdemic roles. Silymarin considered as a mixture of flavonolignan compounds isolated from the seeds of Silybum marianum plant. The most constituents are silibinin, isosilibinin, silicristin and silidianin. These compounds type and quantity differed by the natural environments where the plant was collected.

Therefore the present work aimed to study the chemical and medicinal effect of naturally growing Silybum marianum plant in Egypt (Gharbya Governorate) compared with the Chinese silymarin (Commercial medication) which considered the most widespread in the medical filed these days and the commonly used one, as well as capacity of protection of kidney damage during liver fibrosis, via estimation of biochemical and oxidative stress markers in addition to the histopathological changes.

\section{Materials and methods}

Silymarin (Medical Chinese) and other fine chemicals were obtained from Sigma Chemical Co., U.S.A. All other chemicals and reagents were used of analytical grade.

\section{Pre-extraction sample preparation}

Silybum marianum seeds were collected from some places in El-Garbia Governorate which grows naturally in the clay soil. The seeds were handily separated from waste and then were crushed in a coffee grinder.

\section{Extraction process}

The crushed seeds were subjected to preliminary treatment (defatting); crushed seeds were soaked in suitable volume of hexane overnight. Defatted seeds were extracted by pressurized hot water and lyophilized using lyophilizer (Telstar, Spain). The crude extract was freeze dried then stored at $-20^{\circ} \mathrm{C}$ until use (El-Adawi et al., 2011).

\section{Animals and experimental design:}

The experiments were performed on 72 female Albino rats weighing $120 \mathrm{~g}$ ( $\pm 20 \mathrm{~g})$. They were obtained from Faculty of Veterinary, Cairo University, Egypt. The rats were housed in the laboratory for 1 week before the experimental work and maintained on a standard diet and water available. The temperature in the animal room was maintained at $23 \pm 2{ }^{\mathrm{O}} \mathrm{C}$ with a relative humidity of $55 \pm$ $5 \%$. Light was on a 12:12 h light-dark cycle. The experimental protocol was approved by Local Ethics Committee and Animals Research. The rats were randomly and equally divided into six groups (12 animals each).

Group $1\left(\mathrm{G}_{1}\right)$ : Control group in which animals never received any treatment.

Group $2\left(\mathrm{G}_{2}\right)$ : Ethanol control group in which rats drank an aqueous ethanol solution (10\%, vol. /vol.) as sole drinking fluid for 4 weeks (Faremi et al., 2008).

Group $3\left(G_{3}\right)$ : Silymarin group in which the animals left at normal life as group I and intragastric intubated with (200 mg/100g body weight/day) of the silymarin (Standard drug) for 4 weeks (Tsai et al., 2008).

Group $4\left(\mathrm{G}_{4}\right)$ : Silymarin treated group in which the animals received ethanol for 4 weeks as in group II (The time at which fibrosis occurred), animals treated by oral gavage with silymarin (200 mg/100g body weight/day) for another 4 weeks with continuous drinking alcohol.

Group $5\left(\mathrm{G}_{5}\right)$ : Milk thistle extract group in which the animals left at normal life as group I and intragastric intubated with (200 mg/100g body weight/day) of the Milk thistle extract for 4 weeks (Shaker et al., 2010).

Group $6\left(\mathrm{G}_{6}\right)$ : Milk thistle extract treated group in which the animals received alcohol for 4 weeks as in group II (The time at which fibrosis occurred), animals treated by oral gavage with Milk thistle extract (200 mg/100g body weight/day) for another 4 weeks with continuous drinking alcohol.

At the end of the experimental period, after an overnight fast, the animals were euthanized by diethyl ether.

\section{Blood collection and tissue sampling}

Blood samples from each rat were collected from the eyes by retro-orbital puncture using blood capillary tubes. Blood samples were collected from the orbital plexus in test tubes, blood was incubated at room temperature for 10 minutes and left to clot then centrifuged at 3000 r.p.m 
for $10 \mathrm{~min}$. and the serum were collected, serum was separated and kept in clean stopper plastic vial at $-80^{\circ} \mathrm{C}$ until the analysis of serum parameters. The heart tissues were immediately isolated, cleaned from blood adhering matters, washed in ice-cold saline, dried, weighed and frozen at $-80^{\circ} \mathrm{C}$, the heart tissues were homogenized $(10 \% \mathrm{~W} / \mathrm{V})$ in phosphate potassium buffer $(0.01 \mathrm{M} \mathrm{pH}$ 7.4) and KCl solution (1.15 M) by homogenizer (Hettich model EBA 12R, Germany), then the homogenate was used for the assay of the analysis of tissue parameters.

\section{Estimation of heart function markers:}

- Creatine kinase (CK) was determined in serum by the kinetic method using available commercial kits (Vitro Scient, Egypt) according to the method described by (Zilva and Pannall, 1979).

- Lactate dehydrogenase (LDH) activity was determined in serum by the kinetic method using available commercial kits (Vitro Scient, Egypt) according to the method described by Moss et al., (1987).

\section{Lipid profile parameters}

The cholesterol was determined after enzymatic hydrolysis and oxidation (Allain et al., 1974). The quinoneimine is formed from hydrogen peroxide and 4aminoantipyrine in the presence of phenol and peroxidase. The HDL cholesterol was determined by enzymatic colorimetric. Where phosphotungstic acid and magnesium ions selectively precipitating all lipoproteins except the HDL fraction - cholesterol present in the supernatant can be determined by the same method used for total cholesterol (Lopes-Virella et al., 1977), LDL-cholesterol was assayed colorimetrically (Wieland and Seidel, 1982). Triacylglycerol in serum was assayed colorimetrically (Fassati and Principe, 1982). All lipid profile parameters were measured by using kits from Biodiagnostics Co., respectively.

\section{Measurement of tissues parameters:}

The protein content in the tissues was determined by the method of Lowry et al. (1951).The malondialdehyde (MDA) level is one of terminal products, formed at the time of the of decomposition polyunsaturated fatty acids mediated by free radicals. MDA was measured by the method of Lahouel et al. (2004). Total thiol was measured using DTNB reagent to the method described by Sedlak and Lindsay (1968). The total antioxidant capacity (TAC) was measured using the ferric reducing antioxidant power (FRAP)by the method of described by Benzie and Strain (1999). The catalase (CAT) activity was measured by monitoring $\mathrm{H}_{2} \mathrm{O}_{2}$ (The substrate of the enzyme) decomposition at $240 \mathrm{~nm}$ according to the method described by $\mathrm{Xu}$ et al. (1997). Glutathione -S-transferase activity was estimated through the formation of adduct, due to conjugation of GSH with 1-chloro-2, 4dinitrobenzene (CDNB) by the method of described by Habig et al. (1974). All parameters were measured in heart tissues, respectively.

\section{Histological investigation:}

Three rats from each group were anesthetized intraperitonial with thiopental. The thorax was cut with surgical incision on the sternum and the perfusion was done from left ventricle and right atrium. A rinsing solution was perused before the fixation solution $(10 \%$ neutral buffered formalin). To make rinsing solution, 9.0g $\mathrm{NaCl}$, 25g Polyvinyl Pyrrolidone, 0.25g Heparin, and 5.0g Procain-HCL were dissolved in one liter of water by thorough stirring. The $\mathrm{pH}$ was adjusted to 7.35 with $1 \mathrm{~N}$ $\mathrm{NaOH}$ and twice filtered through Millipore filters of 3.0 $\mu \mathrm{m}$ or less pore size. The perfusion of both solutions was performed by using a scalp vein attached to a 50cc syringe.

Ventricle was immediately removed taking care to handle specimens gently to minimize trauma and put into fixative solution. Fixation time was limited to 24 hours and the fixed tissues were stored in $70 \%$ ethyl alcohol until they were processed. The fixed tissues were dehydrated through a graded series of ethanol and embedded in paraffin according to standard procedures (Latendresse et al., 2002). Paraffin sections ( $5 \mu \mathrm{m}$ thick) were mounted on gelatin chromalum-coated glass slides and some of them were used for Haematoxylin and eosin stains as a routine method after Bancroft and Stevens (1990) and the rest were used for immunohistochemical studies.

\section{Statistical analysis:}

The data ( $\mathrm{n}=12)$ obtained in the experiment was expressed in terms of mean \pm SEM. Statistical significance of data was assessed by one way analysis of variance (ANOVA) followed by a comparison between different groups using "Tukey-Kramer" multiple comparison test. A value of $P<0.05$ was considered to be statistically significant. The ethanol group was compared with the control group and all other treated groups were compared with the ethanol group.

\section{Results}

\section{Food intake, body weight gain and relative organ weight:}

Table (1) showed that the body weight gain of G6 (Fibrosis treated with extract) were highly significant increased $(p<0.001)$ than G1 (Control) and the body weight gain of G2 (Fibrosis) showed a highly significant decreased $(p<0.001)$ than G1 (Control). G3 (Silymarin), G4 (Fibrosis treated by silymarin), G5 (Extract) and G6 (fibrosis treated with extract) were showed a highly significant increase in the body weight gain $(\mathrm{p}<0.001)$ than G2 (Fibrosis). On the other hand G3 (Silymarin) showed a highly significant decreased in the body weight gain $(p<0.001)$ than G4 (Fibrosis treated by silymarin) and G6 (Fibrosis treated with extract). Also G5 (Extract) was highly significant decreased $(p<0.001)$ in the body weight gain than G4 (Fibrosis treated by silymarin). 


\section{Heart function parameter in serum:}

Table (2) showed that the activity of creatine kinasein serum of G1 (Control) was a highly significant increased $(P<0.001)$ than G2 (Fibrosis), while the activity of Creatine kinasein serum of G2 (Fibrosis) showed a highly significant decreased $(P<0.001)$ than G3 (Silymarin), G4 (Fibrosis treated with silymarin), G5 (Extract) and G6 (Fibrosis treated with extract). On the other hand the activity of creatine kinasein serum of G3 (Silymarin) showed a highly significant increased $(P<0.001)$ than G4 (Fibrosis treated with silymarin), G5 (Extract) and G6 (fibrosis treated with extract), while the activity of creatine kinasein serum of G4 (Fibrosis treated with silymarin) showed a significant increase $(P<0.05)$ than G6 (fibrosis treated with extract). Also the activity of creatine kinasein serum of G5 (Extract) showed a significant increase $(P<0.01)$ than G6 (fibrosis treated with extract).

Table (2) also showed that; the activity of lactate dehydrogenase in serum of G1 (Control) was a highly significant decreased $(P<0.001)$ than G2 (Fibrosis), G4 (Fibrosis treated with silymarin) and G6 (Fibrosis treated with extract). On the contrast, the activity of Lactate dehydrogenase in serum of G1 (Control) showed a highly significant increased $(P<0.001)$ than G3 (Silymarin) and G5 (Extract). While the activity of Lactate dehydrogenase in serum of G2 (fibrosis) showed a highly significant increased $(P<0.001)$ than G3 (Silymarin), G4 (Fibrosis treated with silymarin) ,G5 (Extract) and G6 (fibrosis treated with extract). On the other hand the activity of lactate dehydrogenase in serum of G4 (Fibrosis treated with silymarin) showed a highly significant increased $(P<0.001)$ than G5 (Extract) and G6 (Fibrosis treated with extract). Also the activity of lactate dehydrogenase in serum of G5 (Extract) showed a highly significant increased $(P<0.001)$ than G6 (fibrosis treated with extract).

\section{Lipid profiles changes (serum cholesterol, triglycerides, HDL and LDL):}

Table (3) showed the changes in the concentration of serum cholesterol, triglycerides, HDL-C and LDL-C respectively in different groups under study. Concentrations of serum cholesterol, triglycerides, HDL$\mathrm{C}$ and LDL-C were significantly $(P<0.001)$ decreased in G1(Control) when compared with G2 (Fibrosis). In contrast the concentration of serum cholesterol, triglycerides, HDL-C and LDL-C were significantly $(P<0.001)$ increased in G2 (Fibrosis) when compared with the all groups.

\section{Total protein in serum and cardiac tissue:}

Table (4) showed that the change in serum total protein of G1 (Control) was a highly significant increased $(P<0.001)$ than G2 (Fibrosis), while the change in serum total protein of G2 (Fibrosis) showed a highly significant decreased $(P<0.001)$ than the change in serum total protein of G3 (Silymarin), G5 (Extract) and G6 (fibrosis treated with extract). Also, Also, Table (4) showed the change in total protein in heart tissue of G1(Control) was significant increased $(P<0.05)$ than $\mathrm{G} 2$ (Fibrosis), while the change in total protein in heart tissue of G2 (Fibrosis) showed a highly significant decreased $(p<0.001)$ than G3 (Silymarin) and G5 (Extract). On the other hand the change in total protein in heart tissue of G4 (Fibrosis treated with silymarin) showed significant decreased $(P<0.01)$ than G6 (Fibrosis treated with extract). Also the change in total protein in heart tissue of G5 showed significant increased $(P<0.01)$ than G6 (Fibrosis treated with extract).

\section{Heart oxidative stress parameters:}

Table (5) Showed that the catalase enzyme activity (mole/min/g tissue) in heart of G1 (Control) was significantly increased $(P<0.001)$ than G3 (Silymarin), while the catalase activity in heart of G2 (Fibrosis) showed a highly significant decreased $(p<0.001)$ than G3 (Silymarin), G4 (Fibrosis treated with silymarin), G5 (Extract) and G6 (Fibrosis treated with extract). On the other, the catalase activity in heart of G3 (Silymarin) showed a highly significant increased $(p<0.001)$ than G4 (Fibrosis treated with silymarin). Also the catalase activity in heart of G4 (Fibrosis treated with silymarin) showed A significant decrease $(P<0.01)$ than G5 (Extract). on the contrast, the catalase activity in heart of G5 showed significant decreased $(p<0.01)$ than G6 (Fibrosis treated with extract). While, the catalase activity in heart of G6 (Fibrosis treated with extract) showed a highly significant increased $(P<0.001)$ than G4 (Fibrosis treated with silymarin).

Table (5) showed that; the total antioxidant capacity in heart of G1 (Control) was a highly significant increased $(P<0.001)$ than G2 (Fibrosis), G4 (Fibrosis treated with silymarin) and G6 (Fibrosis treated with extract). On the contrast, the total antioxidant capacity in heart of G1 (control) showed a highly significant decreased $(P<0.001)$ than G3 (Silymarin) and G5 (Extract). On the other hand, the total antioxidant capacity in heart of G4 (Fibrosis treated with silymarin) showed a highly significant decreased $(p<0.001)$ than G3 (Silymarin), G5 (Extract) and G6 (Fibrosis treated with extract). While, the total antioxidant capacity in heart of G5 (Extract) showed a highly significant increased $(P<0.001)$ than G6 (Fibrosis treated with extract).

Table (5) showed that the concentrations of lipid peroxidation (MDA) in heart of G1 (Control) was a highly significant decreased $(P<0.001)$ than $\mathrm{G} 4$ (Fibrosis treated with silymarin). While, the concentrations of MDA in heart of G2 (Fibrosis) showed significant decreased $(P<0.05)$ than G4 (Fibrosis treated with silymarin). On the other hand, the concentrations of MDA in heart of G3 (Silymarin) showed a highly significant decreased $(P<0.001)$ than G4 (fibrosis treated with silymarin) and G6 (Fibrosis treated with extract). Also, the concentrations of MDA in heart of G4 (Fibrosis treated with silymarin) showed a highly significant 
increased $(p<0.001)$ thanG3 (Silymarin). While, the concentrations of MDA in heart of G5 (Extract) showed a

treated with extract). Table (5) also showed that; the total thiol in heart of G1 (Control) was a highly significant decreased $(P<0.001)$ than G4 (Fibrosis treated with silymarin). While, total thiol in heart of G2 (Fibrosis) showed significant increased $(P<0.05)$ than $\mathrm{G1}$ (Control). highly significant increased $(p<0.001)$ than G6 (Fibrosis

On the other hand, the total thiol in heart of G3 (Silymarin) showed significant decreased $(P<0.05)$ than G6 (Fibrosis treated with extract). Also, the total thiol in heart of G5 (Extract) showed significant decreased $(p<0.01)$ than G6 (Fibrosis treated with extrac

Table 1: Body weight gain (BW) (g), food intake (g) and relative organ weights of the Heart (g/100 g body weight), of female rats treated with vehicle GP1 (Control), GP2 (Ethanol), GP3 (Chinese Silymarin only), GP4 (Ethanol + Chinesesilymarin), GP5 (Egyptian silymarin extract only) and GP6 (Ethanol + Egyptian silymarin extract), Values are expressed as mean $\pm \mathrm{SEM} ; \mathrm{n}=12$.

\begin{tabular}{|c|c|c|c|c|c|c|}
\hline Parameter & $\mathrm{G}_{1}$ & $\mathrm{G}_{2}$ & $\mathrm{G}_{3}$ & $\mathrm{G}_{4}$ & $\mathrm{G}_{5}$ & $\mathrm{G}_{6}$ \\
\hline B W gain & $20.5 \pm 3.00^{\mathrm{a}}$ & $2.0 \pm 1.25^{\mathrm{ad}}$ & $19.0 \pm 1.60^{\mathrm{dg}}$ & $42.2 \pm 3.30^{\mathrm{adgj}}$ & $20.5 \pm 2.90^{\mathrm{dj}}$ & $43.0 \pm 3.2^{\mathrm{adgm}}$ \\
\hline Food intake & $13.4 \pm 0.37^{\mathrm{b}}$ & $11.3 \pm 0.45^{\mathrm{bd}}$ & $14.4 \pm 0.58^{\mathrm{d}}$ & $15.8 \pm 0.30^{\mathrm{d}}$ & $14.1 \pm 0.33^{\mathrm{d}}$ & $15.7 \pm 0.35^{\mathrm{d}}$ \\
\hline Heart & $0.51 \pm 0.04^{\mathrm{ac}}$ & $0.75 \pm 0.07^{\mathrm{d}}$ & $0.49 \pm 0.03^{\mathrm{di}}$ & $0.55 \pm 0.03^{\mathrm{dij}}$ & $0.43 \pm 0.04^{\mathrm{djm}}$ & $0.54 \pm 0.03^{\mathrm{dm}}$ \\
\hline
\end{tabular}

- The significant of difference was analyzed by one -way ANOVA and Tukey test (compare all pairs of columns)using a computer program (Graph Pad Instate software ,Inc)

- ANOVA was significant at $\mathrm{p} \leq 0.05$

- Groups having The same letters as a or $\mathrm{d}$ or $\mathrm{g}$ or $\mathrm{j}$ or $\mathrm{m}$ were significant at $\mathrm{p} \leq 0.001$

- Groups having The same letters as $b$ or e or $h$ or $k$ or $n$ were significant from each at $p \leq 0.01$

- Groups having The same letters as c or f or i or l or o were significant from each at $\mathrm{p} \leq 0.05$

Table (2): changes in heart function parameter in serum (U/L)of female rats treated with vehicle GP1 (Control), GP2 (Ethanol), GP3 (Chinese Silymarin only), GP4 (Ethanol +Chinesesilymarin), GP5 (Egyptian silymarin extract only) and GP6 (Ethanol + Egyptian silymarin extract), Values are expressed as mean \pm SEM; $\mathrm{n}=12$.

\begin{tabular}{|c|c|c|c|c|c|c|}
\hline Enzyme & $\mathbf{G}_{1}$ & $\mathbf{G}_{2}$ & $\mathbf{G}_{3}$ & $\mathbf{G}_{4}$ & $\mathbf{G}_{5}$ & $\mathbf{G}_{\mathbf{6}}$ \\
\hline $\begin{array}{c}\text { Creatine } \\
\text { kinase }\end{array}$ & $153 \pm 6.47^{\mathbf{a}}$ & $102 \pm 6.31^{\text {ad }}$ & $283 \pm 7.31^{\text {adg }}$ & $203 \pm 6.51^{\text {adgl }}$ & $215 \pm 10.11^{\text {adgn }}$ & $173 \pm 4.18^{\text {dgln }}$ \\
\hline $\begin{array}{c}\text { Lactate } \\
\text { dehydrogenase }\end{array}$ & $821 \pm 2.2^{\mathbf{a}}$ & $1083 \pm 0.9^{\text {ad }}$ & $771 \pm 5.9^{\text {ad }}$ & $949 \pm 0.9^{\text {adg }}$ & $638 \pm 2.1^{\text {adgjm }}$ & $869 \pm 0.6^{\text {adgjm }}$ \\
\hline
\end{tabular}

- The significant of difference was analyzed by one -way ANOVA and Tukey test (compare all pairs of columns) using a computer program (Graph Pad Instate software ,Inc)

- ANOVA was significant at $\mathrm{p} \leq 0.05$

- Groups having the same letters as a or $\mathrm{d}$ or $\mathrm{g}$ or $\mathrm{j}$ or $\mathrm{m}$ were significant at $\mathrm{p} \leq 0.001$

- Groups having the same letters as $\mathrm{b}$ or e or $\mathrm{h}$ or $\mathrm{k}$ or $\mathrm{n}$ were significant from each at $\mathrm{p} \leq 0.01$

- Groups having the same letters as $\mathrm{c}$ or $\mathrm{f}$ or $\mathrm{i}$ or $\mathrm{l}$ or o were significant from each at $\mathrm{p} \leq 0.05$ 
Table (3): Changes serum in cholesterol, triglycerides, HDL-C and LDL-C(mg/dl), of female rats treated of female rats treated with vehicle GP1 (Control), GP2 (Ethanol), GP3 (Chinese Silymarin only), GP4 (Ethanol +Chinese silymarin), GP5 (Egyptian silymarin extract only) and GP6 (Ethanol + Egyptian silymarin extract), Values are expressed as mean \pm SEM; $n=12$.

\begin{tabular}{|c|c|c|c|c|c|c|}
\hline Parameter & $\mathbf{G}_{1}$ & $\mathbf{G}_{2}$ & $\mathbf{G}_{3}$ & $\mathbf{G}_{4}$ & $\mathbf{G}_{5}$ & $\mathbf{G}_{6}$ \\
\hline Cholesterol & $104.9 \pm 2.9^{\mathbf{a}}$ & $211.4 \pm 2.0^{\mathbf{a d}}$ & $88.9 \pm 2.9^{\mathbf{d}}$ & $108.8 \pm 3.2^{\mathbf{d}}$ & $92.8 \pm 3.4^{\mathbf{d}}$ & $86.5 \pm 2.5^{\mathbf{d}}$ \\
\hline Triglycerides & $88 \pm 5.6^{\mathbf{a}}$ & $197 \pm 10.1^{\mathbf{a d}}$ & $79 \pm 5.8^{\mathbf{d}}$ & $141 \pm 7.3^{\mathbf{d}}$ & $63 \pm 5.0^{\mathbf{d}}$ & $135 \pm 3.2^{\mathbf{d}}$ \\
\hline HDL & $39.8 \pm 2.0^{\mathbf{a}}$ & $73.4 \pm 2.6^{\mathbf{a d}}$ & $35.6 \pm 1.0^{\mathbf{d}}$ & $55.3 \pm 2.2^{\mathbf{d}}$ & $34.2 \pm 1.1^{\mathbf{d}}$ & $27.8 \pm 1.9^{\mathbf{d}}$ \\
\hline LDL & $47.4 \pm 3.0^{\mathbf{a}}$ & $98.6 \pm 6.0^{\mathbf{a d}}$ & $37.6 \pm 4.0^{\mathbf{d}}$ & $25.2 \pm 3.7^{\mathbf{d}}$ & $46.1 \pm 3.8^{\mathbf{d}}$ & $27.2 \pm 2.7^{\mathbf{d}}$ \\
\hline
\end{tabular}

- The significant of difference was analyzed by one -way ANOVA and Tukey test (compare all pairs of columns) using a computer program (Graph Pad Instate software,Inc) - ANOVA was significant at $\mathrm{p} \leq 0.05$ Groups having the same letters as a or $d$ or $g$ or $j$ or $m$ were significant at $p \leq 0.001$ - Groups having the same letters as $b$ or e or $h$ or $k$ or $n$ were significant from each at $\mathrm{p} \leq 0.01$

- Groups having the same letters as c or f or i or l or o were significant from each at $\mathrm{p} \leq 0.05$

Table (4): Changes in total protein in serum (g/dl), Heart (mg/ g tissue) in tissues of female rats treated with vehicle. GP1 (Control), GP2 (Ethanol), GP3 (Chinese Silymarin only), GP4 (Ethanol +Chinese silymarin), GP5 (Egyptian silymarin extract only) and GP6 (Ethanol + Egyptian silymarin extract), Values are expressed as mean \pm SEM; $n=12$.

\begin{tabular}{|c|c|c|c|c|c|c|}
\hline & $\mathbf{G}_{\mathbf{1}}$ & $\mathbf{G}_{\mathbf{2}}$ & $\mathbf{G}_{\mathbf{3}}$ & $\mathbf{G}_{\mathbf{4}}$ & $\mathbf{G}_{\mathbf{5}}$ & $\mathbf{G}_{\mathbf{6}}$ \\
\hline S. total protein & $6.1 \pm 0.11^{\mathbf{a}}$ & $4.1 \pm 0.1^{\text {ad }}$ & $4.9 \pm 0.12^{\mathbf{d}}$ & $4.5 \pm 0.12$ & $5.6 \pm 0.08^{\mathbf{d}}$ & $5.4 \pm 0.17^{\mathbf{d}}$ \\
\hline Heart total protein & $17.8 \pm 1.45^{\mathbf{c}}$ & $13 \pm 0.83^{\mathbf{c d}}$ & $20.9 \pm 14.6^{\mathrm{dh}}$ & $14.6 \pm 0.94^{\text {hk }}$ & $20.8 \pm 1.21^{\text {dkn }}$ & $15 \pm 1.04^{\text {hn }}$ \\
\hline
\end{tabular}

- The significant of difference was analyzed by one -way ANOVA and Tukey test (compare all pairs of columns) using a computer program (Graph Pad Instate software ,Inc)

- ANOVA was significant at $\mathrm{p} \leq 0.05$ - Groups having the same letters as a or $\mathrm{d}$ or $\mathrm{g}$ or $\mathrm{j}$ or $\mathrm{m}$ were significant at $\mathrm{p} \leq$ 0.001 - Groups having the same letters as b or e or $h$ or $k$ or $n$ were significant from each at $\mathrm{p} \leq 0.01$

- Groups having the same letters as c or $\mathrm{f}$ or i or $\mathrm{l}$ or o were significant from each at $\mathrm{p} \leq 0.05$

Table (5): Changes in heart tissues oxidative stress parameters \{catalase (CAT) enzymes activities (mole/min/g tissue) and concentrations of MDA (nmole/ g tissue), total thiol (mM/g tissue), total antioxidant capacity ( $\mu$ mole $\mathrm{Fe}^{+2} / \mathrm{g}$ tissue) of female rats treated with vehicle GP1 (Control), GP2 (Ethanol), GP3 (Chinese Silymarin only), GP4 (Ethanol + Chinesesilymarin), GP5 (Egyptian silymarin extract only) and GP6 (Ethanol + Egyptian silymarin extract),Values are expressed as mean $\pm \mathrm{SEM} ; \mathrm{n}=12$.

\begin{tabular}{|c|c|c|c|c|c|c|}
\hline Parameter & $\mathbf{G}_{\mathbf{1}}$ & $\mathbf{G}_{\mathbf{2}}$ & $\mathbf{G}_{3}$ & $\mathbf{G}_{\mathbf{4}}$ & $\mathbf{G}_{5}$ & $\mathbf{G}_{\mathbf{6}}$ \\
\hline CAT & $107.4 \pm 2.6^{\mathbf{a}}$ & $42 \pm 1.1^{\mathbf{d}}$ & $104.8 \pm 3.6^{\text {adg }}$ & $83.8 \pm 1.2^{\mathbf{d g j k}}$ & $115 \pm 1.8^{\mathbf{d k n}}$ & $99.6 \pm 4.0^{\text {djn }}$ \\
\hline TAC & $1.43 \pm 0.03^{\mathbf{a}}$ & $0.67 \pm 0.06^{\text {ad }}$ & $1.99 \pm 0.04^{\text {adg }}$ & $0.99 \pm 0.02^{\text {adg }}$ & $2.41 \pm 0.04^{\text {adgjm }}$ & $1.3 \pm 0.01^{\text {dgjm }}$ \\
\hline MDA & $26.8 \pm 2.2^{\mathbf{a}}$ & $32.8 \pm 2.6^{\mathbf{f}}$ & $28.2 \pm 1.4^{\mathbf{g}}$ & $40 \pm 3.8^{\text {afgj }}$ & $18.4 \pm 1.4^{\text {ejm }}$ & $48.8 \pm 2.4^{\text {egm }}$ \\
\hline Total thiol & $14 \pm 1.2^{\text {ac }}$ & $33 \pm 4.0^{\mathbf{c}}$ & $27.2 \pm 3.6^{\mathbf{i}}$ & $38.6 \pm 6.8^{\mathbf{a}}$ & $25.2 \pm 1.8^{\mathbf{n}}$ & $44 \pm 4.0^{\text {in }}$ \\
\hline
\end{tabular}

- The significant of difference was analyzed by one -way ANOVA and Tukey test (compare all pairs of columns) using a computer program (Graph Pad Instate software ,Inc) - ANOVA was significant at $\mathrm{p} \leq 0.05$ - Groups having the same letters as a or $\mathrm{d}$ or $\mathrm{g}$ or $\mathrm{j}$ or $\mathrm{m}$ were significant at $\mathrm{p} \leq 0.001$ - Groups having the same letters as $b$ or $\mathrm{e}$ or $\mathrm{h}$ or $\mathrm{k}$ or $\mathrm{n}$ were significant from eachat $\mathrm{p} \leq 0.01$

- Groups having the same letters as c or $\mathrm{f}$ or i or $\mathrm{l}$ or o were significant from eachat $\mathrm{p} \leq 0.05$ 

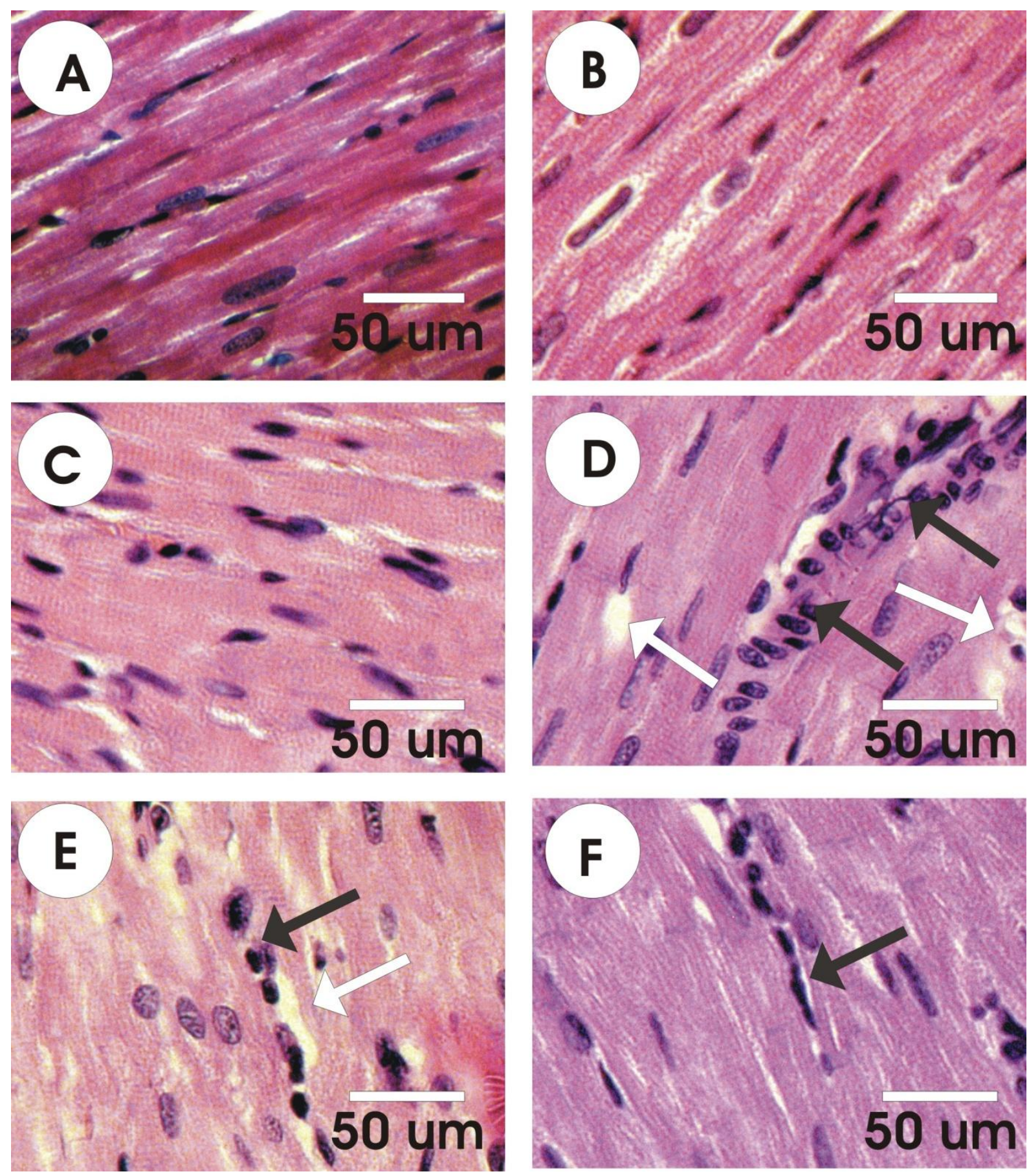

Figures 1A-1F: High power micrographs of rat heart sections stained by haematoxylin and eosin. A-C: Cardiac myocytes of left ventricle in control, silymarin and milk thistle rat groups respectively showing normal myofibrillar structure with normal striations. D:Cardiac myocytes of left ventricle in ethanol rat group revealed hydrophobic changes of myofibrillar structure with striations, myocardial atrophy, nuclear pyknosis and severe cytoplasmic vacuoles. E: Cardiac myocytes of left ventricle in ethanol exposed rats and treated with silymarin revealed mild myocardial atrophy, edema and mild cytoplasmic vacuoles. F:Cardiac myocytes of left ventricle in ethanol exposed rats and treated with s. milk revealed little tissue injury with myocardial atrophy, nuclear pyknosis and a few cytoplasmic vacuoles with decreased in the number of collected cardiac nuclei. 
Table (5) also showed that; the total thiol in heart of G1 (Control) was a highly significant decreased $(P<0.001)$ than G4 (Fibrosis treated with silymarin). While, total thiol in heart of G2 (Fibrosis) showed significant increased $(P<0.05)$ than $\mathrm{G} 1$ (Control). On the other hand, the total thiol in heart of G3 (Silymarin) showed significant decreased $(P<0.05)$ than G6 (Fibrosis treated with extract). Also, the total thiol in heart of G5 (Extract) showed significant decreased $(p<0.01)$ than G6 (Fibrosis treated with extract).

\section{Light Microscopic Examination of rat left ventricle:}

Light microscopy of the rat left ventricle sections in control group (G1) showed normal myofibrillar structure with striations, branched appearance and continuity with adjacent myofibrils (Fig. 1A). Rat left ventricle sections in silymarin and s. milk groups (G3\&G5) revealed a normal myofibrillar structure with striations as in control sections (Figs. 1B \&1C). Histopathological studies of the left ventricle in fibrosis group (G2) revealed hydrophobic changes of myofibrillar structure with striations, moderate myocardial atrophy, marked nuclear pyknosis, severe cytoplasmic vacuoles, edema, leukocyte infiltration, in addition to cross striations were lost with increased in the number of cardiac nuclei that collected outside the myofibrillar (Fig. 1D). Left ventricle sections in ethanol exposed rats and treated with silymarin (G4; Fibrosis treated with silymarin) for six weeks revealed myocardial atrophy, mild cytoplasmic vacuoles, edema and leukocyte infiltration (Fig. 1E). Left ventricle sections in ethanol exposed rats and treated with s. milk (G6; Fibrosis treated with extract) for six weeks revealed little cardiac tissue injury with a few myocardial atrophy, no nuclear pyknosis, and a decrease in the number of collected cardiac nuclei (Fig. 1F).

\section{Discussion}

Liver fibrosis induction by alcohol has determined by rat's weight, food efficiency, heart enzymes, lipid profile and oxidative status (Das and vasudevan, 2005; Shaker et al., 2010). The current results of the current study indicated significant decrease in the body weight gain and food intake of animals treated with ethanol as compared with control group, while, the presence of silymarin and MTE with ethanol alleviated its toxic effects. Also, Saravanan and Nalini (2007) and Das and vasudevan, (2005) mentioned that ethanol treatment led to decrease body weight gain and food intake. The result of the present study showed that increase in relative organ weight of heart in animals treated with ethanol in comparison with the control. No significant change was observed in relative weights of heart in ethanol treated groups compared to the control group (Das et al., 2008).

Treatment with MTE and silymarin increased the heart weight as compared to ethanol group. Tedesco et al. (2004) reported that the extract increases the elimination of ethanol directly from the intestines without absorption or perhaps because $S$. marianum and silymarin consumption prevents fat accumulation in the liver. The relationships between alcohol and cardiovascular function and disease are inherently complex. The present data indicated that LDH was significantly increased in ethanol treated group and this is in accordance with the results reported by Noorani and Kale (2012). We suggested that silymarin and MTE extract appeared to be normal in the value of LDH reported that the results at this stage as well indicate the positive effect of silymarin in prevention of ethanol misuse consequences.

The present results showed that the animals treated with ethanol showed significant increased in the serum level of cholesterol, triglyceride, LDL and HDL compared to the control group. Silymarin and MTE decreased the elevation of TC, TG, HDL and LDL, suggesting the hepato protective effect of silymarin. The antihypercholesterolemic effect of silymarin was associated with liver cholesterol reduction, which improves cholesterol uptake from blood (Kreeman et al., 1998). This is in accordance with the results reported by Shaker et al. (2010) and El-Adawiet al. (2011).

The present data indicated that the heart total protein and the serum total protein were significantly decreased in ethanol treated group. This result is hand on hand with the findings of Hessien et al (2010) and Reddy et al. (2010). Treatment with silymarin and MTE raised the protein level suggesting the stabilization of endoplasmic reticulum required for protein synthesis. These findings were in accordance with the results reported by Noorani and Kale (2012).

In our study, the tissue damage produced by high level of MDA in heart in group treated with the ethanol as compared with the control group. While, our result showed significant increase in total thiol in heart in ethanol group as compared with the control group. As well, the MTE and silymarin treated group showed significant decreased for MDA levels and significant increased in total thiol level as antioxidant content when compared with ethanol group. These data are agreed with that reported by Raja et al. (2007) and Toklu et al. (2008).Our results suggested the protective effects of silymarin, which include antioxidation, prevention of lipid peroxidation (Basaga et al., 1997) and retarding glutathione depletion (Alidoost et al., 2006).

Brighenti et al (2005) reported that moderate alcohol drinking can increase TAC, where as daily and higher ingestion of alcoholic beverages reduce blood TAC. In our results, ethanol consumption daily for 30 days showed a reduction in TAC in heart tissues in group treated with ethanol as compared to the control group. In contrast, groups treated with MTE and silymarin showed elevation in TAC in heart tissues when compared to ethanol group. This is in accordance with the results reported by Amin et al. (2012).

Catalase present in the peroxisomes of nearly all aerobic cells, serves to protect the cell from the toxic effects of 
hydrogen peroxide by catalyzing its decomposition into molecular oxygen and water without the production of free radicals. The detoxification of 4-hydroxynonenal is compromised when GST level is reduced. Thus, ethanol or its metabolic products might specifically target GST isoenzymes and the reduction in enzyme activity or expression may contribute to ethanol hepatotoxicity (Hiratsuka et al., 2001). CYP2E1 could be the sole catalyst of fetal ethanol oxidation produces 1-hydroxy ethyl radicals, which have been shown to inactivate several proteins including antioxidant enzyme system (Epstein, 1996). In consistent with these reports, our results also showed that decreased activities of CAT heart tissues on the group treated with ethanol as compared to the control group.

In current study, treatment with MTE and silymarin showed increased the activities of CAT in heart tissues. These results were in the same line as with those results reported by Das and Vasudevan (2006). This may happen due to the essential activity of silymarin is an antioxidant effect of its flavonolignan and of other poly-phenolic substituent, which is attributed to the radical scavenging ability of both free radicals and reactive oxygen species (Nencini et al., 2007).

Histological and immunohistochemical results of this study confirms biochemical result where as markedly pathological changes of myocardiocytes including multifocal vacuolar degeneration and early necrosis of myocardial cells as well as separation of cardiac muscle bundles in group treated with ethanol in comparison with control group which showed normal myofibrillar structure with striations, branched appearance and continuity with adjacent myofibrils. Also, Rat left ventricle sections in silymarin and s. milk groups revealed a normal myofibrillar structure with striations which agreed with Aleksandar et al, 2011.In ethanol group which co-treated with silymarin for six weeks, Left ventricle sections revealed myocardial atrophy, mild cytoplasmic vacuoles, and edema and leukocyte infiltration. Where as in group that co treated with s. milk for six weeks, Left ventricle sections revealed little tissue injury with myocardial atrophy, nuclear pyknosis, a few cytoplasmic vacuoles and decrease in the number of collected cardiac nuclei. These results were in the same line as those reported by Chlopeikova et al, 2004.

\section{Conclusion}

Our results reported that the Silybum marianum seed could be extended for the isolation and structure determination of hepatoprotective and heart protective principle. Silymarin capable of caused marked alteration in some biochemical parameters induced oxidative damage and inhibited the activities of antioxidant enzymes. While, silymarin administrated in combination with ethanol had a beneficial effect, in the therapy of ethanol-induced liver fibrosis. In addition, silymarin alone prove to be beneficial in decreasing the levels of free radicals and lipid, and increasing antioxidant enzymes.
Consequently, the result proved the activity of Milk thistle extract in comparable to the standard drug silymarin. Furthermore the seeds of the plant may be added as a nutrition supplement for domestic animals farm.

\section{References}

Aleksandar R, Stilinović N, Kolarović J, Vasović V, Vukmirović S and Mikov M. 2011. The protective effects of silymarin against doxorubicin-induced cardiotoxicity and hepatotoxicity in rats. Molecules,16: 8601-8613.

Alidoost F, Gharagozloo M, Bagherpour B, Jafarian A, Sajjadi SE, Hourfar H, Moayedi B. (2006): Effects of silymarin on the proliferation and glutathione levels of peripheral blood mononuclear cells from betathalassemia major patients. IntImmunopharmacol, 6:1305-1310.

Allain CC, Poon LS, Chan Cicely SG., Richmond W, and Fu Paul C. (1974): Enzymatic Determination of Total Serum Cholesterol. Clinical Chemistry, 20: 470475.

Amin ZA, Bilgen M, Alshawsh MA, Ali HM, Hadi AH, Abdulla MA. (2012): Protective role of Phyllanthusniruri extract against thioacetamide-induced liver cirrhosis in rat model. Evid Based Complement Alternat Med, doi: 10.1155/2012/241583.

Anthony K, Subramanya G, Uprichard S, Hammouda F, and Saleh M. (2013): Antioxidant and Anti-Hepatitis C Viral Activities of Commercial Milk Thistle Food Supplements.Antioxidants,2: 23-36.

Ashak KG, Zimmerman HJ, Andray MB. (1991): Alcoholic liver disease: Pathologic, pathogenic and clinical aspects. Alcohol: Clinical and Experimental Research 15:45-66.

Bancroft JD, Steven A. (1990): Theory and Practice of Histological Technique ( $3^{\text {rd }}$ ed.) NY: Churdchilllivingstone. pp: 42: 107-110.

Basaga H, Poli G, Tekkaya C, Aras I. (1997): Free radical scavenging and antioxidative properties of 'silibin' complexes on microsomal lipid peroxidation. Cell Biochem Funct; 15:27-33.

Benzie IFF, Strain JJ. (1996): The ferric reducing ability of plasma(FRAP) as a measure of " antioxidant power': the FRAP assay. Analytical Biochemistry, 239: 70-76.

Brighenti F, Valtuena S, Pellegrini N, Ardigo D, Del Rio D, Salvatore S, Piatti PM, Serafini M, Zavaroni I. (2005): Total plasma antioxidant capacity of the diet is inversely and independently related to plasma concentration of high-sensitivity C-reactive protein in adult Italian subjects. Brit J Nutr; 93:619-625.

Chlopeikova A, Psotova J, Miketova P, Simanek V. (2004): Chemopreventive effect of plantphenolics 
against anthracycline-induced toxicity on rat cardiomyocytes. Part I.Silymarin and its flavonolignans. Phytother Res, 18: 107-110.

Das SK, Varadhan S, Dhanya L, Mukherjee S, Vasudevan DM. (2008): Effects of chronic ethanol exposure on renal function tests and oxidative stress in kidney. Ind J Clin Biochem, 23:341-344.

Das SK, Vasudevan DM. (2005): Effect of ethanol on liver antioxidant defense systems: Adose dependent study. Indian Journal of Clinical Biochemistry. 20(1):8084.

Das SK, Vasudevan DM. (2006): Protective effects of silymarin, a milk thistle (Silybummarianum) derivative on ethanol- induced oxidative stress in liver. Ind J BiochemBiophys,43:306-311.

El-Adawi H, El-Azhary D, Abd El-wahab A, ElShafeey M, Abdel-Mohsen M. (2011): Protective effect of Milk thisle and grape seed extracts on fumonisin B1 induced hepato- and nephro- toxicity inrats. J. Med. Plants Res. 5(27):6316-6327

Epstein M. (1996): In: Epestin M. (Ed.) $4^{\text {th }}$ ed., Renal Sodium Handling in Liver Disease. The Kidney in Liver Disease. Hanley and Belfus Publication: Philadelphia; 1-31.

Faremi TY, Suru SM, Fafunso MA, Obioha UE. (2008): Hepatoprotective potentials of Phyllanthusamarus against ethanol-induced oxidative stress in rats. Food ChemToxicol.46(8):2658-2664.

Fossati P, Principe L. (1982): Serum triglycerides determined calorimetrically with an enzyme that produces hydrogen peroxide. Clinical Chemistry, 28: 2077-2080.

Lowry OH, Rosebrough NJ, Farr AL. and Randall R. J. (1951): Protein measurement with Folin phenol reagent. J. Biol. Chem., 193: 265-275.

Friedman S.L. (2003): Liver fibrosis - from bench to bedside. J. Hepatol. 38 (Suppl. 1), (S) 38-53.

Gupta S, Pandey R, Katyal R, Aggarwal HK, Aggarwal RP, Aggarwal SK. (2005): Lipid peroxidase levels and antioxidant status inalcoholic liver. Ind. J. Clin.Biochem. 20 (1): 67-71

Habig WH, Pabst MJ, Jakoby WB (1974): Glutathione S-transferases: the first enzyrnatic step in rnercapturic acid formation. J. biol. Chem. 249: 71307139.

Halton DW, Day TA, Fried B, Maule AG and Mair GR. (2001): Muscle organisation of Schistosoma mansoni ceracria. J Parasitol.122: 447-455.

Hessien MH, El-Sharkawi IM, El-Barbary AA, ElBeltagy DM, Snyder N. (2010): Non-invasive index of liver fibrosis induced by alcohol, thioacetamide and Schistosomal infection in mice. BMC Gastroenterol, 10:53.doi: 10.1186/1471-230X-10-53.
Hiratsuka A, Tobita K, Saito H , Sakamoto Y, Nakano H, Ogura K, Nishiyama T, Watabe T. (2001): (S)-preferential detoxification of 4-hydroxy-2(E)nonenalenantiomers by hepatic glutathione S-transferase isoforms in guinea-pigs and rats. Biochem. J. 355:237344.

Kaškonienė $\mathrm{V}$, Kaškonas $\mathrm{P}$, MaruškaA, Ragažinskienė O. (2011): Chemical composition and chemometric analysis of essential oils variation of Bidenstripartita L. during vegetation stages. Acta Physiology Plant. 33: 2377-2385.

Kreeman V, Skottova N, Walterova D. (1998): Silymarin inhibits the development of diet-induced hypercholesterolemia in rats. Planta Med. 64:138-142.

Lahouel M, Boulkour S, Segueni N, and Fillastre JP.(2004): The flavonoids effect against vinblastine, cyclophosphamide and paracetamol toxicity by inhibition of lipid-peroxidation and increasing liver glutathione concentration. Pathol. Biol. 52 (D): 314-322.

Latendresse J R, Warbrittion AR, Jonassen $\mathrm{H}$, and Creasy DM. (2002): Fixation of testes and eyes using a modified Davidson's fluid: comparison with Bouin's fluid and conventional Davidson's fluid. Toxicol Pathol, 30: 524-533.

Lavoie JP and Tuesher E. (1993): Massive iron overload and liver fibrosis resembling haemochromatosis in a racing pony. Equin Vet J. 25(6): 552-554.

Liu Yan-ze, Lee David Yue-wei. (2012): Standardization and identification of minor components of silymarin (MK-001). Chin Herb Med, 4:237-244.

Lohse AW, Knoll M, Meyer Z, Bushenfeld KH and Cohen IR. (1995): Mode of aummunization and Tcell reactivity to liver antigens in the induction of experimental autoimmune hepatitis. J Hepatol. 23(1): 130-138.

Lopes-Virella MF, Stone P, Ellis S. (1977): Cholesterol determination in high density lipoprotein separated by three different methods. Clin. Chem, 23: 882.

Low T, Leow C, Salto-Tellez $\mathrm{M}$ and Chung $\mathrm{M}$. (2004): A proteomic analysis of thioacetamide - induced hepatotoxicity and cirrhosis in rat livers. Proteomics, 45(3): 25-30

Moss DW, Henderson AR and Kachmar JF. (1987): Enzymes. In Fundamentals of Clinical Chemistry, pp 372-373. Ed NW Tietz. Philadelphia, PA, USA: WB Saunders Company.

Nencini C, Giorgi G, Micheli L.(2007): Protective effect of silymarin on oxidative stress in rat brain. Phytomedicine, 14:129-135.

Noorani AA, Kale MK. (2012): Pretreatment of albino rats with methanolic fruit extract of 
Randiadumetorum (L.), protects against alcohol induced liver damage. Korean J Physiol Pharmacol; 16:125-130.

Poynard T, McHutchison J, Goodman Z (2000): Is an a la carte combination interferon alfa-2b plus ribavirin regimen possible for the first line treatment in patients with chronic hepatitis C? Hepatology, 31: 211-218.

Raja S, Ahmed K, Kumar VMukherjee K, Bandyopadhyay A, Mukherjee P. (2007): Antioxidant effect of Cytisusscoparius against carbon tetrachloride treated liver injury in rats. J Ethnopharm, 109: 41-47.

Reddy VD, Padmavathi P, Paramahamsa M, Varadacharyulu N.C.(2010): Amelioration of alcoholinduced oxidative stress by Emblicaofficinalis (Amla) in rats. Ind J Biochem Biophys; 47:20-25.

Saravanan N, Nalini N.(2007): Impact of Hemidesmusindicus R. Br. extract on ethanol-mediated oxidative damage in rat kidney. Redox Rep, 12:229-235.

Sedlak J and Lindsay RH. 1968. Estimation of total, protein-bound, and non protein sulfhydryl groups in tissue with Ellman's reagent. Anal Biochem., 25(1):192205.

Shaker, E., Mahmoud, H., Mnaa, S. (2010) Silymarin, the antioxidant component and Silybummarianum extracts prevents liver damage. Food and Chemical Toxicology 48, 803-806.

Sternberger L. A. (1979): The Unlabelled Antibody Peroxidase- Antiperoxidase (PAP) Method. In: "immunocytochemistry", $2^{\text {nd }}$ Edn., (Cohen S, and McCluskyRT.ed.). John Wiley and sons, New York.pp: 104-169.

Tedesco D, Domeneghini C, Sciannimanico D, Tameni M, Steidler S, Galletti S. Silymarin, a possible hepatoprotector in dairy cows: biochemical and histological observations. J Vet Med A Physiol Pathol Clin Med 2004;51:85-9.

Toklu H, Akbay T, Velioglu-Ogunc A, Ercan F, Gedik N, Keyer-Uysal M, Sener G. Silymarin, the antioxidant component of Silybum marianum, prevents sepsis-induced acute lung and brain injury. J Surgical Res 2008;145:214-22.

Tsai, J.H., Liu, J.Y., Wu, T.T., Ho, P.C., Huang, C.Y., Shyu, J.C., Hsieh, Y.S., Tsai, C.C., Liu, Y.C. 2008. Effects of sylimarin on the resolution of liver fibrosis induced by carbontetrachloride in rats. Journal of Viral Hepatitis, 15,508-514,.

Wieland, H., and D. Seidel. 1982. Improved assessment of plasma lipoprotein patterns. IV. Simple preparation of a lyophilized control serum containing intact human plasma lipoproteins. Clin. Chem. 2 8; 13351337.

Wolf, P., 1999. Biochemical diagnosis of liver diseases. Ind. J. Clin. Biochem. 14, 59-90.
Xu, J.B., Yuan, X.F. and Lang, P.Z. 1997. Determination of catalase activity and catalase inhibition by ultraviolet spectrophotometry. Chin. Environ. Chem. 16,73

Zilva, J.F., and Pannall, P.R. 1979.Plasma Enzymes in Diagnosis in Clinical Chemistry in Diagnosis and Treatment. Lloyd-Luke, London. 